\title{
Utilization of Recycled Polyethylene Terephthalate (PET) in Engineering Materials: A Review
}

\author{
M. Sulyman, J. Haponiuk, and K. Formela
}

\begin{abstract}
In general, the quantity of plastics of all types consumed annually all over the world has been growing in a phenomenal way. The manufacturing processes, service industries and municipal solid wastes (MSW) generate numerous waste plastic materials. The increasing awareness about the environment has tremendously contributed to the concerns related with disposal of the generated wastes. It is believed that the management of solid waste is one of the major environmental concerns in the world. Due to limited space on landfills and increasing costs of plastics, utilization of waste plastics has become an attractive alternative for disposal. This paper provides a summary of experimental efforts on the utilization of poly(ethylene terephthalate) (PET) in civil engineering projects, mainly in road pavement, cements and concretes. Presented data indicate that use of waste PET for modification of asphalt, cement and concretes improved their selected properties, which makes economical this approach. Furthermore, using of waste PET in building materials reduce usage of new polymeric materials, which has significant effect on environment pollution (e.g. emission of carbon dioxide, waste disposal problems, etc.)
\end{abstract}

Index Terms-Bitumen, building materials, concrete, PET, recycling.

\section{INTRODUCTION}

Plastics are commonly used substances which play an important role in almost every aspect of our lives. The widespread generation of plastics waste needs proper end-of-life management. The highest amount of plastics is found in containers and packaging's (i.e. bottles, packaging, cups etc.), but they also are found in durables (e.g. tires, building materials, furniture, etc.) and disposable goods (e.g medical devices) [1]. Diversity of plastics applications is related with their specific properties, low density, easy processing, good mechanical properties, good chemical resistance, excellent thermal and electrical insulating properties and low cost (in comparison to other materials).

Post-production and post-consumer plastics are utilized in a wide range of applications. However, in this field two main direction should be mentioned: 1) using of plastic waste as alternative fuel (burning) in cement kilns and power plants and 2) material recycling of waste polymers.

According to the U.S. Environmental Protection Agency (USEPA 1992), the municipal solid waste (MSW) generated in the United States is $200,000,000$ tons/year, among them about $38 \%$ wt being paper products, $8 \%$ wt plastic, and $3 \% \mathrm{wt}$

Manuscript received January 22, 2015; revised May 12, 2015.

The authors are with the Department of Polymer Technology, Chemical Faculty, Gdansk University of Technology, Poland (e-mail: mohsulym76@yahoo.com). carpets and textiles [2]. In the year of 1996, content of plastics in MEW raised to $12 \%$ wt [3]. The world's annual consumption of plastic materials has increased from around 204 million tons in the 2002 to nearly 300 million tons in 2013 [4]. Moreover, production and consumption of polymers and plastics will be constantly growing in next year. In Table I estimated data about types and quantities of polymers in MSW stream generated annually in United States are presented. As we can see main stream of plastic waste in MSW are thermoplastics polymers poly(ethylene), poly(propylene), poly(styrene) and poly(ethylene terephthalate).

TABLE I: TYPES AND QUANTITIES OF PLASTICS IN MSW IN THE USA [5], [6]
\begin{tabular}{|l|c|}
\hline \multicolumn{1}{|c|}{ Type of plastic } & Quantity (1000 tons) \\
\hline Low density polyethylene (LDPE) & 5010 \\
\hline High density polyethylene (HDPE) & 4120 \\
\hline Polypropylene (PP) & 2580 \\
\hline Polystyrene (PS) & 1990 \\
\hline Polyethylene Terephthalate, (PET) & 1700 \\
\hline Others & 3130 \\
\hline
\end{tabular}

In India approximately 40 million tons of the municipal solid waste is generated annually, with evaluated increasing at a rate of 1.5 to $2 \%$ every year. Plastics constitute to around $12.3 \%$ wt of the total MSW. It is worth to notice, that the most of plastics fraction are drinking bottles which are made mainly of PET [7].

Plastic (polymers) used for applications in bitumen modifications, can be subdivided into two main types depending on their behavior after exposure to heat. First type are thermosetting polymers (e.g. resins, elastomers) which are cured during heating. Three-dimensional structure of cross-linking bonds formed during curing unable softening of polymer matrix and its easy re-processing. Second type are thermoplastic polymers. This type of polymers can be shaped and designed in new shapes using heat. In contrary to thermosetting polymers this process is reversible. Examples of aforementioned materials are shown in the Table II [8]. The plastics used for bitumen modification may be also classified as thermoplastic and thermosets.

TABLE II: EXAMPLES OF THERMOPLASTICS AND THERMOSETTING MATERIALS

\begin{tabular}{|l|l|}
\hline \multicolumn{1}{|c|}{ Thermoplastics } & \multicolumn{1}{c|}{ Thermosetting } \\
\hline Polyethylene Terephthalate (PET) & Bakelite \\
\hline Polypropylene (PP) & Epoxy resins \\
\hline Polyvinyl Acetate (PVA) & Melamine resins \\
\hline Polyvinyl Chloride (PVC) & Polyesters \\
\hline Polystyrene (PS) & Polyurethane \\
\hline Low density polyethelene (LDPE) & Urea - Formaldehyde \\
\hline High density polyethylene (HDPE) & Alkyd resins \\
\hline
\end{tabular}


This paper presents a detailed review about using of waste PET in road pavement asphalt and also building concretes.

\section{Polyethylene Terephthalate (PET)}

Poly(ethylene terephthalate) (PET) is the most commonly used thermoplastic polyester. It is often called just "polyester," which often causes confusion, because polyester resins are thermosetting materials. PET is a transparent polymer, with a good mechanical properties and good dimensional stability under variable load. Moreover, PET has good gas barrier properties and good chemical resistance [9].

Abovementioned properties of PET caused its wide application in the form of bottles, thermally stabilized films (e.g. capacitors, graphics, film base and recording tapes etc.) and electrical components. PET is also used for production of fibers for a very wide range applications in textile industry.

PET belongs to a thermoplastics with excellent physical properties [10]. It constitutes is around $18 \%$ of the total polymers produced worldwide and over $60 \%$ of its production is used for synthetic fibers and bottles, which consume approximately $30 \%$ of global PET demand [11].

\section{SOURCES OF PET WASTES}

Waste PET source can be categorized into three main stream: a) Bottles - small problems with material recycling; problems related with impurities (e.g. glue on labels), different types additives used during production (e.g. stabilizers, pigments), molecular weight of PET, etc., which are affecting on repeatability of obtained products. b) Foils small problems with material recycling; problems related with additives used during production (e.g. stabilizers, pigments), molecular weight of PET, etc., which are affecting on repeatability of obtained products. c) Cord from tires - huge problem with material recycling. Currently, this fraction of waste PET is used as alternative fuel. Example of waste tire cord is presented in Fig. 1 and its composition in Table III. Waste tire cord can be significant and cheap source of valuable poly(ethylene terephthalate). The main problem during material recycling of waste tire cord are contaminations of ground tire rubber and metals.

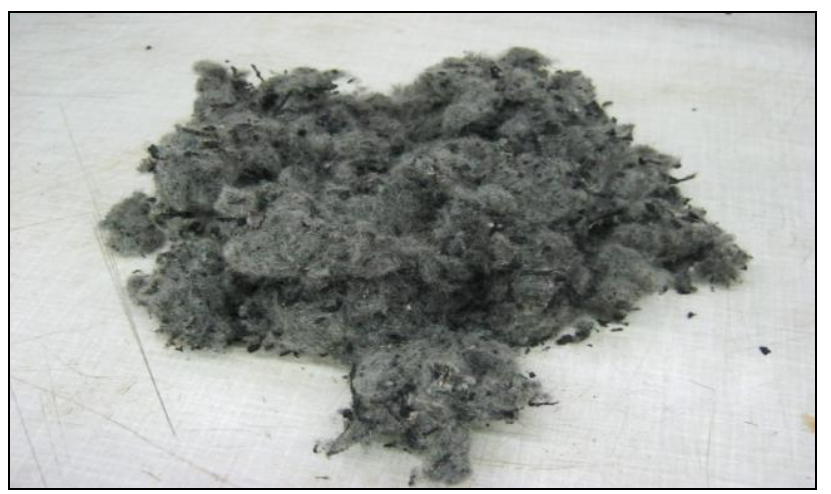

Fig. 1. Recycled textile fiber from used tires.

Other methods of overcoming the problems of waste PET through recycling processes may include the incorporation of PET with asphalt binders as a modifier for asphalt used at road constructions [12], [13] and as reinforcement material for concrete and other building materials by partial substitution for the fine aggregates (i.e. sand) [14]. These approaches are usually intended to improve the engineering properties and increase the service life of modified materials. In this way, it appears that it is a viable rout contribution to both achieving economical benefits, and to decrease the environmental impact of waste tire cord.

TABLE III: COMPOSITIONS OF WASTE TIRE CORD

\begin{tabular}{|l|c|}
\hline \multicolumn{1}{|c|}{ Compositions } & Weight percent (\%) \\
\hline Poly(ethylene therephthalate) (PET) & 77.6 \\
\hline Polyamide (PA) & 18.7 \\
\hline Polypropylene (PP) & 3.7 \\
\hline
\end{tabular}

\section{Utilization of PET In AsPhalt PaVEMENT}

Recycling of waste PET plastics can make significant contribution to environment and economy from different aspects. It helps to reduce the exploitation of natural resources to reduce the environmental pollution level, saving energy and money, and it contributes to modifying the physical and engineering properties of construction materials such as asphalt and building concrete.

Asphalt has been widely used in road pavement construction as the binder of aggregates [15]. However, it is well recognized that asphalt mixture or coating layer shows severe temperature susceptibility such as high temperature rutting, medium temperature fatigue and low temperature cracking damage (Fig. 2). Therefore, asphalt mixture modification is sometimes used to improve its further application.

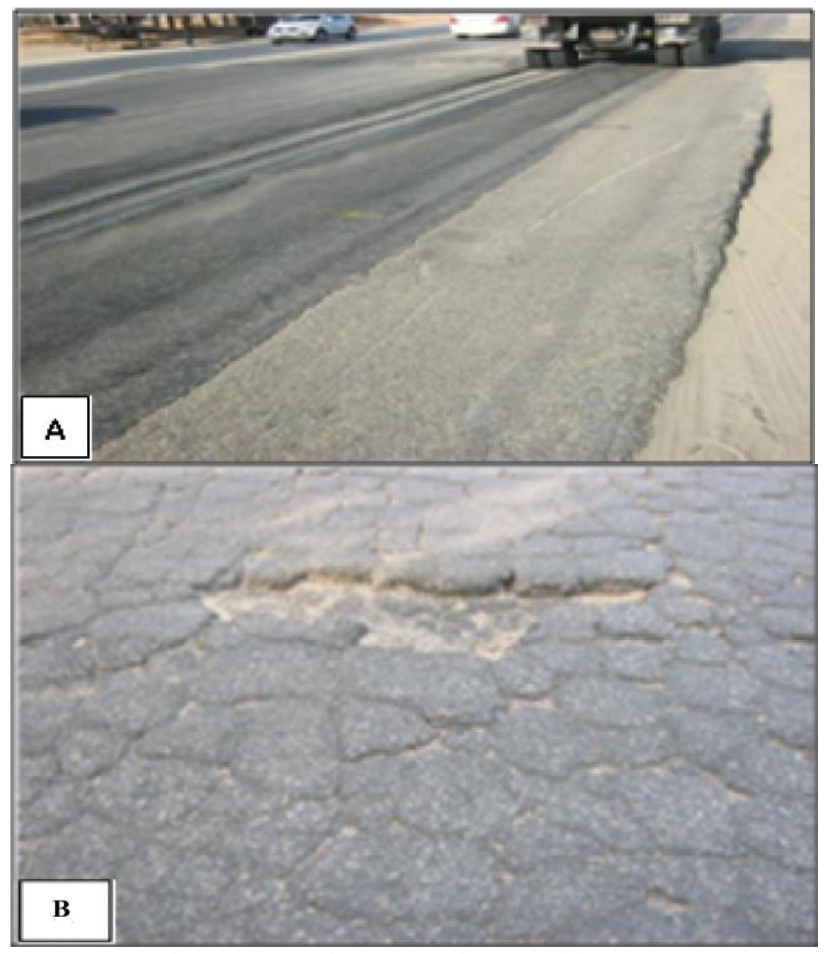

Fig. 2. (A) Rutting; (B) Fatigue cracking [16].

Improvements in asphalt properties sometimes can be achieved by either selecting the proper starting crude oil, or by controlling the refinery processes aimed at making desired asphalts, which are both unfortunately very difficult to attain [17]. Therefore, the popular method for improvement of 
asphalt quality is its modification. Air blowing makes asphalt harder. Fluxing agents or diluent oils are sometimes used to soften the asphalt. Another method that can significantly improve asphalt quality is the addition of polymers [17]. Asphalt modification with polymers is a common method for improvement of rheological properties of asphalt [18].

A very important property of the asphalt mixture is its ability to resist shove and rutting under long-lasting traffic and traffic loading repetitions. Therefore, asphalt stability should be suitable enough to handle traffic adequately. The lack of stability in an asphalt mixture means unraveling and flow of the road surface. Flow is the ability of hot mixture asphalt (HMA) pavement to adjust to gradual settlements and movements in the subgrade without cracking [19].

The viscoelastic properties of the asphalt are significantly affected by the chemical composition and hence they have a direct effect on asphalt performance. Pavements defects such as rutting at high temperatures, cracking at low temperature region and others are due not only to traffic loads but also to the capability of the asphalt concrete to sustain temperature changes. Increased traffic factors such as heavier loads, higher traffic volume, and higher tire pressure demand higher performance of road pavements. A higher performance pavement requires asphalt that is less susceptible to high temperature rutting or low temperature cracking, and has excellent bonding to stone aggregates.

The uses of virgin polymers in asphalt to improve the characteristics of the resulting polymer modified asphalt have been accomplished for many years [19]. Nevertheless, recently there is an interest in the substitution of commercial virgin material by recycled polymers e.g. shredded waste plastic containers made of PET. Reclaimed rubber obtained from waste tires has been also used with positive effects in pavements [19].

Substitutions technique for asphalt in pavements, including the hot mix and the cold mix by polymers such as PET, is put into practice for the improvement of rutting resistance, thermal cracking, fatigue damage, stripping, and temperature susceptibility. They are used when extra performance and durability are desired. In many cases, they are selected to reduce life cycle costs [17]. Polymer modified binders also show improved adhesion and cohesion properties [20].

The high cost of polymers compared to asphalt means that the amount of polymer necessary for improved pavement performance should be as small as possible. From an environmental and economic point of view, it is possible to imagine the possibility of disposing of waste plastics such as PET bottles within road asphalts because similarity in performance is found between recycled polymers and virgin polymers modified asphalt. Thus, the use of CR (crumb rubber) from used tires or thermoplastic polymers such as $\mathrm{PE}$, PET, or EVA, as an asphalt-modifying agent may contribute to solve a waste disposal problem and to improve the quality of road pavements [18]. Many polymers have been used as binder modifiers, and they can be classified into a number of groups, each with advantages and disadvantages as asphalt modifiers [17].

The main reasons to modify asphalts with plastics are: 1) obtaining softer blends at low service temperatures and reducing cracking, 2) obtaining stiffer blends at high temperatures and reducing rutting, 3) reduceing viscosity, 4) increasing the stability and the strength of mixtures, 5) improving the abrasion resistance and fatigue resistance of blends, and oxidation and aging resistance, 6) reducing structural thickness and life costs of pavements [21].

It is well known that polymers can successfully improve the performance of asphalt pavements at almost all temperatures by increasing mixture resistance to fatigue cracking, thermal cracking and permanent deformation [22].

\section{A. Case Studies}

Vasudevan et al. [23] studied the utilization of waste polymers at production of flexible pavements. In presented studies, authors coated the stone aggregates with molten waste plastics. They concluded that the coating of aggregates with plastics reduced the porosity, absorption of moisture and improved soundness. They found that the use of waste plastics for flexible pavement was one of the best methods for easy disposal of waste plastics.

Regarding the use of polymer (plastic) wastes for asphalt modification, those mentioned in the literature are mainly low density polyethylene (LDPE) [24], high density polyethylene (HDPE) [25], polypropylene (PP) [26], ethylene-vinyl acetate (EVA) [27], [28], acrylonitrile-butadiene-styrene (ABS) [26], polyethylene terephthalate (PET) [29] and polyvinyl chloride (PVC) [30]. 2007; Awwad and Hbeeb [31] have investigated the improvement of asphalt modified with polyethylene (PE). Their studies have been also carried out to determine the best type of PE to be used and its proportion in the asphalt mixture. HDPE and LDPE were two types of PE added to coat the aggregate. Data analysis proved that grinded HDPE polyethylene modifier provided better engineering properties. The recommended proportion of the modifier was $12 \%$ by weight of asphalt content. It was also found to increase the stability, reduce the density and slightly increase the air voids and the voids of mineral aggregate.

Polyethylene(PE) the most popular plastic material, has been found to be one of the most effective polymer additives for asphalt [32]. Polyethylene is the most popular plastic in the world. Polyethylene is a semi-crystalline material with excellent chemical resistance, good fatigue, good wear resistance and low price.

A study on the effect of PE on the modified asphalt properties was conducted by Fuentes-Audén et al. [33]. They have concluded that PE incorporation in the asphalt shold not exceed $5 \%$, otherwise the resulting viscosity would reduce the processability of the mixture. Addition of recycled PE promotes better resistance to rutting, cracking and to thermal fatigue.

According to the study of García-Morales et al. [27], the modification of asphalt with recycled EVA led to very satisfying results. In their work, concentrations which were studied ranged from 0 to $9 \%$ wt. The results have also indicated that the recycled EVA has increased the binder viscosity at higher service temperatures, with consequent benefits on road performance, such as resistance to rutting. However, the asphalt viscosity at the production and application temperatures demonstrated to be sufficiently low for its adequate use in pavements even at concentrations as high as $9 \%$. 
Casey et al. [26] have concluded that waste HDPE and LDPE were the most promising recycled materials that can be used for asphalt modification, when compared with recycled PET, PVC and ABS. They have expected better results to be obtained with ABS, and pointed out to a concentration of $4 \%$ as the ideal concentration of recycled HDPE and LDPE used as additives in the asphalt binder.

Comparably, a work done by Costa et al. [34] aimed to evaluate the possible advantages of modifying the asphalt binder with different plastic wastes: HDPE, LDPE, EVA, $\mathrm{ABS}$ and $\mathrm{CR}$ (crumb rubber), in order to improve the properties of the resulting asphalt binders. The performance of modified binders with recycled polymers was compared with that of the conventional asphalt and the one of a commercial modified binder. The characterization of the different asphalts modified with 5\% of each one of the studied polymers demonstrated that it is possible to obtain similar properties, or even better, than those of commercial modified asphalt. In fact, it was observed that: SBS, HDPE and EVA are the most promising polymers to increase the softening point of the modified binder; HDPE and EVA are the polymers with higher influence in the penetration test results; SBS, EVA and CR (elastomers) presented the best performance in relation to resilience; all modified asphalts, excluding those with $\mathrm{ABS}$ and $\mathrm{CR}$, only reach the proper viscosity to produce asphalt mixtures near or above $180{ }^{\circ} \mathrm{C}$, including the commercial asphalt; HDPE, LDPE and EVA have a good dispersion in the asphalt, whereas SBS, ABS and $\mathrm{CR}$ are difficult to be melted in the asphalt. This phenomenon was related with viscosity of used modifiers, which were affecting on their flowability an dispersibility in asphalt matrix.

PET, the most abundant plastic waste material collected for recycling from the household waste stream as mentioned by Action Program (WRAP) survey [35], may be used as an additive and modifier for asphalt binder. This was investigated by a number of researchers and many reports and scientific studies on this subject were published in the last years.

The application of waste PET; a thermoplastic polymer resin of the polyester family, in the form of granules pellet of $3 \mathrm{~mm}$ size was part of a study carried out by Hassean et al. [36]. They blended the waste PET as a partial fine aggregate with an asphalt binder (from 60/70 penetration grade asphalt and $12.5 \mathrm{~mm}$ aggregate grading) at $(140-180){ }^{\circ} \mathrm{C}$ and then compacted it using Marshall hammer with 50 blows on each side. The results obtained in this study proved that the aggregate replacement of $20 \%$ fine aggregate $(2.36-4.75$ $\mathrm{mm}$ ) by volume with PET granulates (5\% total weight of the asphalt mixture) was the effective use to get the highest Marshall Quotient with the lowest flow and the highest of stability.

In addition, PET has been found to be the most effective polymer additives due to its low glass transition temperature and semicrystallinity [19].

A number of investigations were focused on the influence of fiber additives on the engineering properties of asphalt binder or asphalt mixture. In SMA, the hot asphalt is coated over hot stone aggregate mixed, laid and rolled. Asphalt acts as a binder. The significant disadvantages of SMA mixes belong to the action of water, which penetrates and causes defective spots on the pavement, when stagnating over the roads. The use of anti stripping agents has a limited use only and the process also increases the cost of road construction [37]-[40]. The use of virgin or waste plastics and plastic coated aggregates to improve the performance of asphalt against this defect has been studied. The improvements of the asphalt mixes were done in a number of attempts by incorporating various types of additives to asphalt such as rubber latex, CR, SBS, SEBS, recycled PP, LDPE [41] PE [42], EVA (5\%) [43] and polyolefines [44], [45]. Some of the properties improved are durability, fatigue life [46], [47], resistance to rutting, softening point, viscoelastic property [48].

Other fiber modifiers from the polyester family were among the modifiers of asphalt, and have obtained more and more attention for their excellent improvement effects. Cellulose fibers, and mineral fibers are two types of commonly used fiber modifiers. They have been widely used in different kinds of asphalt mixtures, especially in stone mastic asphalt (SMA); it is a type of HMA with open grade friction concrete (OGFC) [47], [48].

SMA was developed in Germany in 1960s and has been using among European countries for more than 20 years [13], [49], [50].

In 2004, a comparison study carried was carried out by Putman and Amirkhanian [51] to investigate the performance of SMA mixtures containing waste CR from used tires, and carpet fibers with commonly used cellulose in one occasion and polyester fibers in the other. The results indicated that the. significantly improved the toughness of the mixtures, but no significant difference in permanent deformation or moisture susceptibility was found.

Polyester fibers are usually used when strong and durable reinforcements of asphalt-fiber mastics are needed at higher temperatures; as it was reported by Shiuh and Kuei [52]. The influence of polyester and cellulose fiber additives on the engineering properties of asphalt was also investigated by [52]. They have found that good adhesion between the polyester fibers and asphalt enhanced the load-carrying ability of asphalt-fiber mastics.

The type of mixing or the process involved in production of very effective asphalt road pavements is very important factor in determining the final product properties. In 1987, an available report has implied the successful application of BoniFibers $^{\mathrm{TM}}$; it is the trade name for polyester fibers of $6 \mathrm{~mm}$ length manufactured in the city of Tacoma, United States of America and supplied to blend with asphalt. The report stated that in order to assure uniform distribution of BoniFibers ${ }^{\mathrm{TM}}$ throughout the asphalt concrete, BoniFibers ${ }^{\mathrm{TM}}$ must be added to the aggregate at the beginning of the dry-mix cycle which lasts at least $15 \mathrm{~s}$ and preferably $30 \mathrm{~s}$ [21].

The assessments of the engineering properties of SMA mixture and the effect of incorporating scrap from waste PET bottles was the center of the study conducted by Esmaeil et al. (2012). The mechanical properties of asphalt mixes that include various percentages of PET $(0 \%, 2 \%, 4 \%, 6 \%, 8 \%$ and $10 \%$ ) were calculated and assessed with laboratory tests. The results showed that the appropriate amount of PET was found to be $6 \%$ by weight of asphalt. Additionally, the 
incorporation of PET has also a significant positive effect on the properties of SMA such as increasing viscosity and stiffness of asphalt at normal service temperatures. However, all applied amounts of PET additives did not increase the elasticity of asphalt significantly and on heating, they do not perform satisfactory [53].

Using plastic waste materials in road pavement can be either in form of aggregate replacement, binder modifier or mixture reinforcement. The last option was selected by Moghaddam and Karim in their study [13] when they investigated the effects of adding waste PET particles into the asphalt mixture. The results of the study showed that PET reinforced asphalt mixtures had higher stability value in comparison with the virgin mixture. In terms of the convenient quantity of the PET to be added, it was noted that the optimum value in case of stability was $0.4 \%$ PET. Moreover, adding higher amounts of PET into the mixture increased the flow values. In contrast, stiffness of the mixture was decreased, yet fatigue life was increased by adding higher amount of PET.

Kalantar et al. (2010) [20], have investigated the possibility of using polyethylene terephthalate as polymer additives in Bituminous Mix. The binders were prepared by mixing the PET in amount of $2 \%, 4 \%, 6 \%, 8 \%$, and $10 \%$ by the weight of optimum bitumen at $150^{\circ} \mathrm{C}$. Results showed better resistance aginst permanent deformations and rutting when compared to conventional binders. The result also showed that the addition of PET to bitumen increases the softening point value, and as the higher PET content increases the softening point temperature increases. This phenomenon indicates that the resistance of the binder to the effect of heat is increased and it will reduce its tendency to soften in hot weather.

Low Density Polyethylene (LDPE) was also used in asphalt mixtures as an aggregate replacement. It was reported that Marshall Stability was increased by $250 \%$, and mix density was reduced by $15 \%$ with the replacement of $30 \%$ LDPE in form of aggregates particles with the size of 2.36-5mm [13].

\section{Utilization of WASTE PET in CONCRETE}

Concrete is a heterogeneous composite material made up of cement, sand, coarse aggregate and water mixed in a desired proportion based on the strength requirements. Concrete is the most frequently used construction material worldwide. However, it is characterized with a number of defects such as low tensile strength, low ductility, heavy weights, and low energy absorption [54]. These main disadvantages have triggered civil engineers to make use of conventional reinforcement to increase the tensile strength and ductility of concrete.

The addition of fibers to concrete would act as crack inhibitors and substantially improve the tensile strength, cracking resistance, impact strength, wear and tear, fatigue resistance and ductility of the modified concrete. The concept of using fibers in concrete as reinforcement is not new one. For last three decades numerous studies were performed on Fiber Reinforced Concrete (FRC). In the early 1960's only straight steel fibers were used and the major improvement occurred in the areas of ductility and fracture toughness, the flexural strength increases were also reported. In the beginning fiber reinforced concrete was primarily used for pavements and industrial floors. Currently, the fiber reinforced cement composite is being used for wide variety of applications including bridges, tunnels, canal linings, hydraulic structures, pipes, explosion resistance structures, safety valves, cladding and rolled compacted concrete [55].

\section{A. Case Studies}

A number of scientific reports [56]-[60] concluded that an effective way to improve the toughness of concrete is adding a small fraction (usually $0.5-2 \%$ by volume) of short fibers to the concrete mix during mixing. In the fracture process of fiber reinforced concrete (FRC), fibers stimulates the bridging between cracks in the matrix and thus provide resistance to crack propagation and crack opening before being pulled out or stressed to rupture. After extensive studies it is widely reported that such fiber reinforcement can significantly improve the tensile properties of concrete.

Other benefits of FRC include improved fatigue strength, wear resistance, and durability. Using FRC instead of conventional concrete, section thickness can be reduced and cracking can be effectively controlled, resulting in lighter structures with longer life expectancy. FRC is currently being used in many applications, including buildings, highway overlays, bridges, and airport runways [57]-[59]. In load bearing applications it is generally used along with traditional steel reinforcement [61]. In building construction it has become a more common practice to use small quantities of synthetic fiber reinforcement for floor slabs.

Many fibers have been used for concrete reinforcement and some are widely available for commercial applications. They include steel, glass, carbon, nylon, polypropylene and others.

Studies have indicated that many forms of fibers recovered from various MSW streams are suitable for concrete reinforcement. The advantages of using such recycled fibers include generally lower cost to process than virgin fibers, and the elimination of the need for waste disposal in landfills.

In addition to the advantages of recycling MSW such as plastics, the incorporation of plastics such as PET wastes in concretes is sometimes essential for the creation of construction building materials with a number of characteristics. Lightweight aggregate is an important characteristics which researches intend to approach in development of building construction material. The reduction of the unit weight of concrete is one of goals at production of earthquake resistant structures since the earthquake forces are linearly dependant on the mass of the structure [62].

Nowadays, there are many lightweight concrete applications made with natural or artificial lightweight aggregates in the literature [63]-[66]. However, the cost of artificial lightweight aggregate production is high due to requirement of high incineration temperature or thermal treatment [67].

As an alternative way of creating lightweight concrete, different from the common materials, using waste plastic granules as lightweight aggregate in the production of lightweight concrete was studied. This has attracted much attention from the researchers. This approach provides benefits of both recycling of the plastic waste and production 
of a lightweight concrete in an economical way [68].

Some of the plastic wastes used in lightweight concrete were PP, PE, PET and PS. The PET bottles were ahead of the wastes with its high increasing speed of consumption. In few years ago, a lot of experimental studies were conducted on using waste PET bottles in concrete reinforcement [69]-[71] . Nowadays, construction engineers intend to utilize polymer concrete which is produced by partially replacing of cement binder with polymer resins. Comparatively, the cost of polymer concrete resins is still higher than of cement based materials, because of the high cost of virgin resins. However, waste PET bottles recycling combined with production of polyester resin decreases the cost of resin manufacture when compared to conventional normal resin production [70]. Unsaturated polyester resin based on recycled PET can be used to produce a good-quality polymer concrete [72]. However, the cost of producing polymer concrete from waste plastics is still high. The other alternative method reported by Silva et al. in 2005 and Ochi et al. in 2007 propose the use of waste PET bottles in the form of PET fibers to produce a lower-in-cost fiber reinforced concrete [56], [73]. The disadvantage of such method is the small volumetric amount of fiber content in the fiber reinforced concrete which is between $(0.3-1.5) \%$. In this way, only small of such waste may be utilized. Using of shredded waste PET bottles directly as aggregate in the concrete or mortar production is considered the most economical use of waste PET bottles in concrete, thus, provide benefits in waste disposal and reduce pollution of environment since natural mineral aggregates resources remain unused. Limited research has been carried out on using waste PET granules as aggregate in concrete or mortar. In these studies, PET and the other plastic wastes (PE and PP) were used together by partially replacing of mineral aggregates [74]-[76]. Marzouk et al. (2007) used waste PET granules as aggregate in lightweight concrete. Authors concluded that, plastic bottles shredded into small PET particles may be used successfully as substitution of aggregates in cementinous concrete composites [76].

Reuse of PET and other plastics as well as of CR wastes in building industry is an effective approach in both preventing environmental pollution and designing economical buildings. The increase in acknowledging and utilizing environmentally friendly, low cost and lightweight construction materials in building industry call for the need for searching more novel, flexible and versatile composites; as it was proposed in the work [77]. Some researchers found that the most important aspects of novelty might be the development of integrated insulation products such as waste polymer added mortars, concretes and bricks [77]-[79]. As a part of this interest, establishment of an appropriate thermal test technique is also a challenge for developing and manufacturing of such products [80].

One of the popular applications concerning the concrete reinforcement particularly for the Portland cement concrete in the last few decades is the incorporation of crumb rubber from used tires (CR). Works [81], [82] presented excellent overviews of such studies. Waste PET bottles have earlier been used in making lightweight aggregates to improve concrete mechanical properties [74].

PET recycling for forming thermal-insulating materials for the building industry has been another feasible application [83]. A work related to enhancement of concrete's thermal insulation performance was carried out using waste shredded PET bottle and pieces of CR. They are added into ordinary concrete-mix. Five different concrete samples (one neat concrete, one concrete with scrap rubber pieces and three concretes with waste PET bottle pieces) were considered. Thermal insulation performances of these samples were examined by the adiabatic hot-box technique, recently proposed by the authors [84]. The results revealed that proper addition of selected waste materials into concrete can significantly reduce heat loss or improve thermal insulation performance. The degree of improvement in thermal insulation is found to vary with the added waste material and geometry of shredded-pieces.

Flexural strength of concrete is another property of concrete which was an aim of a study by Venu and Rao [55], They have conducted an experimental investigation on flexural strength of fiber reinforced concrete slabs and compared to plain concrete slabs. They involved the examination of five different slabs two contained steel fibers, two with synthetic macro fibers, namely waste PET and waste HDPP and one plain concrete slab. They were $(2.2 \times 2.2) \mathrm{m}$ in size and nominal thickness of $127 \mathrm{~mm}$ after being casted. The authors found that ultimate load carrying capacity of concrete increased by $4.62 \%$ with $1 \%$ HDPP fiber and by $9.11 \%$ with $1 \%$ PET fiber; the compressive strength of concrete increased by $4.2 \%$ with $1 \%$ HDPP fiber and $5.63 \%$ with $1 \%$ PET fiber, and load carrying capacity of concrete in flexure was increased by using both fibers when compared to plain concrete slabs.

In a similar issue, flexural behavior of small steel fiber reinforced concrete slabs studied by Ali and Majid . They found that the addition of steel fibers in the concrete improves the energy absorption capacity of slabs [85].

In addition to the aforementioned, Shaikh Faiz Uddin Ahmed et al. [86] investigated strain hardening and multiple cracking behavior of hybrid fiber reinforced cement composites containing different hybrid combinations of steel and polyethylene (PE) fibers under four point bending. Consequently, hybrid combination of $1.5 \%$ steel and $1.0 \%$ polyvinyl alcohol (PVA) exhibited best performance in terms of highest flexural strength, $0.5 \%$ steel and $2.0 \%$ PE exhibited highest deflection and highest energy absorption capacities.

The behavior of glass fiber reinforced concrete slabs was studied by Ombres et al. [87]. As a result, they found that the ultimate capacity of slabs increases with the amount of GFRP rebars while Andrea and Kanrod [88] found that the compressive strength and ductility are increased by using fibers, when conducting experiments on concrete using different fibers like steel, glass, carbon and hemp.

Ms K. Ramadevi and Ms R. Manju [89] have investigated the possibility of using the waste PET bottles as the partial replacement of aggregate in Portland cement. In their investigation, $0.5 \%, 1 \%, 2 \%, 4 \%$ and $6 \%$ volume of sand was replaced by PET bottle fibers. Based upon the experimental results of this study, the following conclusion were drawn: 1) the compressive strength and split tensile strength were increased up to $2 \%$ replacement of the fine aggregate with PET bottle fibers and it gradually decreased for $4 \%$ and $6 \%$ 
replacements, 2) the flexural strength increased up to $2 \%$ replacement of the fine aggregate with PET and it gradually decreased for $4 \%$ and remains the same for $6 \%$ replacements, 3 ) the replacement of the fine aggregate with $2 \%$ of PET bottle fibers was reasonable than other replacement percentages like $4 \%$ and $6 \%$ as the compression and split tensile strength reduces gradually.

Karim et al. [90] studied the structural behavior of polymer concrete (PC) beams using PET in the concrete. Their results showed that the beams exhibited higher strength and more ductility than base concrete beams, also recycling of PET in PC helps in saving energy and in partially solving a solid waste problem posed by plastics.

Nibudey et al. [91] studied the waste plastic fiber reinforced concrete (WPFRC) by using several design concrete mixes with different percentages (0\% to $3 \%)$ of waste plastic fibers. The major conclusions based on the results obtained in this study as follows: 1) the workability property of concrete was affected in WPFRC, 2) the maximum percentage increase in compressive strength, split tensile strength and flexure strength at $1 \%$ of fiber content compared to control concrete, 3 ) the dry density was reduced and made concrete light weight, 4) the behavior of WPFRC was found ductile due inclusion of fibers, 5) the optimum strength was observed at $1 \%$ of fiber content for all types of strengths.

\section{FINAL REMARKS}

The major remarks based on the information gathered from scientific literatures are as follows:

Case studies based on researches and experimental works and scientific reports proved that plastic wastes and especially recycled PET may be applied for modifications of road pavement asphalt and also building concretes.

Case studies proved that improvements of road pavement asphalt and also building concretes in terms of performance in the first and reinforcement in the second are both can be attained by the addition of little amounts of a number of different polymer binders.

\section{REFERENCES}

[1] Plastic Common Wastes \& Materials US EPA. (2013). [Online]. Available: www.epa.gov/osw/conserve/material/plastic.htm

[2] U.S. Environmental Protection Agency (USEPA), "Characterization of municipal solid waste in the United States," EPA/530-S-92-019 Rep., Washington, D.C. 1992.

[3] Franklin Associates Ltd., "Characterization of municipal solid waste. Update (Prepared for the USEPA) Prairie Village," KS, USA, 1998.

[4] Europe Plastics - the Facts 2014/2015: An analysis of European latest plastics production, demand and waste data, Brussels, Belgium: Plastics Europe, 2013.

[5] R. Siddique, J. B. Khatib, and K. Inderpreet, "Use of recycled plastic in concrete: A review," Waste Management, vol. 28, pp. 1835-1852, 2008.

[6] P. M. Subramanian, "Plastics recycling and waste management in the US," Resource, Conservation and Recycling, vol. 28, pp. 253-263, 2000 .

[7] K. Ramadevi and R. Manju, "Experimental investigation on the properties of concrete with plastic PET (bottle) fibres as fine aggregates," International Journal of Emerging Technology and Advanced Engineering, vol. 2, no. 6, p. 42, 2012.

[8] A. Gawande, G. Zamare, V. C. Renge, S. Tayde, and G. Bharsakale, "An overview on waste plastic utilization in Asphalting of roads,"
Engineering Research and Studies Journal, vol. 3, no. 2, pp. 1-5, 2012.

[9] A. S. Jabarin, "Polyethylene terephthalate chemistry and preparation," The Polymeric Materials Encyclopedia, CRC Press Inc., 1996.

[10] L. Menachem and E. Pearce, Handbook of Fiber Chemistry, Second Edition, Marcel Dekker Inc., 1998.

[11] L. Bottenbruch, Engineering Thermoplastics: Polycarbonates, Polyacetals Polyesters, and Cellulose Esters, Hanser/Grander Publications Inc., 1996.

[12] B. Yuonne and M. P. M. R. Yajaira, "Polymer modified asphalt," Vision Technologica, vol. 9, no. 1, pp. 39-48, 2001.

[13] T. B Moghaddam and M. R. Karim, "Propeties of SMA mixtures containing waste polyethylene terephthalate," World Academy of Science, Engineering and Technology, vol. 6, pp. 612-622, 2012.

[14] C. Swaptik, T. A. Maniar, and O. Suganya, "Polyethylene terephthalate (PET) waste as building solution," International Journal of Chemical, Environmental \& Biological Science, vol. 1, no. 2, 2013.

[15] N. Akmal and A. M. Usmani, "Application of asphalt-containing materials," Polym News, vol. 24, pp. 136-40, 1999.

[16] M. Sulyman, M. Sienkiewicz, and J. Haponiuk, "New study on improved performance paving asphalt by crumb rubber and polyethylene modification," J. Material Sci Eng., vol. 2, no. 4, 2013.

[17] B. Yuonne and M. P. M. R. Yajaira, "Polymer modified asphalt," Vision Technologica, vol. 9, no. 1, pp. 39-48, 2001.

[18] O. G. Uranga, "Rheological property of bitumen modified with polyethylene and polyethylene based blends," 2008.

[19] N. K. Lu, "Effect of astragalus on characteristics of asphalt concrete," Journal of Materials in Civil Engineering, vol. 11, no. 4, pp. 283-286, 1999.

[20] Z. N. Kalantar, "Properties of bituminous binder modified with waste polyethylene terephtalate," presented at Malaysia Universities Transportation Research Forum and Conferences, December 21, 2010, Universiti Tenaga Nasional.

[21] L. H. Lewandowski, "Polymer modification of paving asphalt binders," Rubber Chemistry and Technology, pp. 447-480, 1994.

[22] S. Aflaki and N. Tabatabaee, "Proposals for modification of Iranian bitumen to meet the climatic requirements of Iran," Journal of Construction and Building Materials, vol. 10, no. 1, pp. 1-10, 2008.

[23] R. Vasudevan, S. K. Nigam, R. Velkennedy, A. R. C. Sekar, and B. Sundarakannan, "Utilization of waste polymers for flexible pavement and easy disposal of waste polymers," in Proc. International Conference on Sustainable Solid Waste Management, Chennai, India, pp. $105-111$.

[24] M. García-Morales, P. Partal, F. J. Navarro, and C. Gallegos, "Effect of waste polymer addition on the rheology of modified bitumen," Fuel, vol. 85, no. 7-8, pp. 936-943, 2006.

[25] E. Hınıslığlu and E. Ağar, "Use of waste high density polyethylene as bitumen modifier in asphalt concrete mix," Materials Letters, vol. 58, no. 3-4, pp. 267-271, 2004.

[26] D. Casey, C. McNally, A. Gibney, and M. D. Gilchrist, "Development of a recycled polymer modified binder for use in stone mastic asphalt," Resources Conservation and Recycling, vol. 52, no. 10, pp. 1167-1174, 2008.

[27] M. García-Morales, P. Partal, F. J. Navarro, F. Martinez-Boza, C. Gallegos, O. González, and M. E. Munoz, "Viscous properties and microstructure of cycled EVA modified bitumen," Fuel, vol. 83, no. 1, pp. 31-38, 2004.

[28] U. Isacsson and X. Lu, "Characterization of bitumens modified with SEBS, EVA and EBA polymers, Journal of Materials Science, vol. 34, pp. 3737-3745, 1999.

[29] E. Ahmadinia et al., "Performance evaluation of utilization of waste polyethylene terephthalate (PET) in stone mastic asphalt," Construction and Building Materials, vol. 36, pp. 984-989, 2012.

[30] Z. N. Kalantar, M. R. Karim, and A. Mahrez," A review of using waste and virgin polymer in pavement," Construction and Building Materials, vol. 33, pp. 55-62, 2012.

[31] M. T. Awwad and L. Shbeeb, "The use of polyethylene in hot asphalt mixtures," American Journal of Applied Sciences, vol. 4, no. 6, pp. 390-396, 2007.

[32] S. Hinisliglu and E. Agar, "Use of waste high density polyethylene as bitumen modifier in asphalt concrete mix," Journal of Materials letters, vol. 58, pp. 267-271, 2004.

[33] C. Fuentes-Audén, J. A Sandoval, A. Jerez, F. J Navarro, F. J. Martínez-Boza, P. Partal, and C. Gallegos, "Evaluation of thermal and mechanical properties of recycled polyethylene modified bitumen," Polymer Testing, vol. 27, no. 8, pp. 1005-1012, 2008.

[34] L. M. B. Costa, H. M. R. D. Silva, J. R. M. Oliveira, and S. R. M. Fernandes, "Incorporation of waste plastic in asphalt binders to 
improve their performance in the pavement," Int. J. Pavement Res. Technol, vol. 6, no. 4, pp. 457-464, 2013.

[35] Waste and Resource Action Programme (WRAP), "Annual local authorities plastics collection survey," 2007.

[36] A. Hassan, H. Ganjidoust, and A. A. Maghanaki, "Use of plastic waste (polyethylene terephthalate) in asphalt concrete mixture as aggregates replacement," J. Waste Managements and Research, vol. 23, no. 4, pp. 322-327, 2005.

[37] T. S. Shuler, J. H. Collins, and J. P. Kirkpoatrick, "Polymer modified asphalt properties related to asphalt concrete performance," Asphalt Rheology Relationship to Mixture, ASTM: STP: 941, O.E, Briscoe Ed ASTM, Philadelphia, 1987.

[38] N. F. Moghadas, E. Aflaki, and M. A. Mohammadi, "Fatigue behavior of SMA and HMA mixtures," Construct Build Mater, vol. 24, pp. $1158-1165,2010$

[39] S. E. Zoorab and L. B. Suparma, "Laboratory Design and performance of improved bituminous composites utilizing recycled plastics packaging waste," in Proc. Technology Watch and Innovation in the Construction Industry, Brussels, Belgium, April 5-6, 2000, pp. 203-209.

[40] J. H Denning and J. Carswell, "Improvements in rolled asphalt surfacing by the addition of organic polymers," Department of the Environment Department of Transport. Report LR 989, Transportation Road Research Laboratory (TRRL), Crow Throne, 1981.

[41] R. J. Salter and F. Rafati-Afshar, "Effect of additives on bituminous highway pavement materials evaluated by the indirect tensile test," Transportation Research Record, no. 1115, 1987, pp. 183-195.

[42] D. N. Little, An additive of asphalt additives to reduce permanent deformation and cracking in asphalt pavements: A brief synopsis of ongoing research," in Proc. the Association of Asphalt Paving Technologists, vol. 55, 1986, pp. 314-320.

[43] W. J. Tappeinier, "Performance and economical advantage of polymer modified asphalt," Richard Felisinger, Vienna, Austria, 1999.

[44] S. Bose and P. K. Jain, "Laboratory studies on the use of organic polymers in improvement of bituminous road surfacing," Highway Research Bulletin, vol. 38, 1989, New Delhi.

[45] S. Bose et al., "Characterization of polymer modified asphalt binders for roads and air field surfacing, polymer modified asphalt binders," American Society of Testing Materials, Philadelphia, USA, pp. 331-355.

[46] G. N. King, H. W. Muncy, and J. B. Prudhome, "Polymer modification: Binder's effect on mix properties," in Proc. the Association of Asphalt Paving Technologists, vol. 55, 1986, pp. 519-540.

[47] J. P. Serfass and J. Samanous, "Fiber-modified asphalt concrete characteristics, application and behavior," Journal of Association of Asphalt Paving Technologists, vol. 65, pp. 193-230, 1996.

[48] T. Süreyya, O. Halit, and A. Atakan, "Investigation of rutting performance of asphalt mixtures containing polymer modifiers," Constr Build Mater, vol. 21, no. 2, pp. 328-37, 2007.

[49] M. I. Asi, "Laboratory comparison study for the use of stone matrix asphalt in hot weather climates," J Constr Build Mater., vol. 20, pp. 982-989, 2006.

[50] R. B. Schmiedlin, "Stone matrix asphalt: The wisconsin experience," Trans. Res. Record: J. Trans. Res. Board, 1988, pp. 34-41.

[51] B. J. Putman and S. N. Amirkhanian, "Utilization of waste fibers in stone matrix asphalt mixtures," Resour Conserv Recc., vol. 42, pp. 265-274, 2004.

[52] J. Shiuh and L. Kuie-Yi, "Mechanisms and behaviour of bitumen strength reinforcement using fibers," J. Mater. Sci., vol. 40, pp. 87-95, 2005.

[53] E. Ahmadinia et al., "Performance evaluation of utilization of waste polyethylene terephthalate (PET) in stone mastice asphalt," Construction and Building Materials Journal, vol. 36, pp. 984-989, 2012.

[54] R. N. Nibudy et al., "Strength and fracture properties of post cinsumed waste plastic fiber reinforced concrete," International Journal of Civil, Structural, Environmental and Infrastructure Engineering Research and Development, vol. 3, no. 2, pp. 9-16. 2013.

[55] V. Malagavelli and P. N. Rao, "Effect of non-degradable waste in concrete slabs," International Journal of Civil and Structural Engineering, vol. 1, no. 3, pp. 449-457, 2010.

[56] D. A. Silva, A. M. Betioli, P. J. P. Gleize, H. R. Roman, L. A. Gomez, and J. L. D. Ribeiro, "Degradation of recycled PET fibers in portland cement-based materials," Cement and Concrete Research, vol. 35, pp. 1741-1746, 2005.

[57] American Concrete Institute (ACI), "State-of-the-art report on fiber reinforced concrete," Committee 544 Rep., ACI 544.1R-82, Detroit, 1982.
[58] J. G. Keer, "Fiber reinforced concrete," New Reinforced Concretes: Concrete Technology and Design, Surrey University Press, vol. 2, pp. $2-105,1984$.

[59] A. Bentur and S. Mindess, Fiber Reinforced Cementitious Composites, London: Elsevier, 1990.

[60] Y. Wang, S. Backer, and V. C. Li, "An experimental study of synthetic fiber reinforced cementitious composites," J. Mat. Sci., vol. 22, pp. 4281-4291, 1987.

[61] American Concrete Institute (ACI), "Design consideration for steel fiber reinforced concrete," Committee 544 Rep., ACI 544.4R-88, Detroit, 1988.

[62] A. Kilic, C. D. Atis, E. Yasar, and F. Ozcan, "High strength lightweight concrete made with scoria aggregate containing mineral admixtures," Cement and Concrete Research, vol. 33, no. 10, pp. 1595-1599, 2003

[63] I. B. Topcu and T. Uygunoglu, "Properties of autoclaved lightweight aggregate concrete," Building and Environment, vol. 42, no. 12, pp. 4108-4116, 2007.

[64] D. S. Babu, G. K. Babu, and T. H. Wee, "Properties of lightweight expanded polystyrene aggregate concretes containing fly ash," Cement and Concrete Research, vol. 35, pp. 1218-1223, 2005.

[65] E. Yasar, C. D. Atis, A. Kilic, and H. Gulsen, "Strength properties of lightweight concrete made with basaltic pumice and fly ash," Materials Letters, vol. 57, pp. 2267-2270, 2003.

[66] R. Demirboğa and R. Gül, "The effects of expanded perlite aggregate, silica fume and fly ash on the thermal conductivity of lightweight concrete," Cement and Concrete Research, vol. 33, pp. 723-727, 2003.

[67] I. B. Topcu, Concrete Technology, Ugur Press, Eskisehir, Turkey, 2006.

[68] H. Koide, M. Tomon, and T. Sasaki, "Investigation of the use of waste plastic as an aggregate for lightweight concrete," Sustainable Concrete Construction, London, pp. 177-186, 2002.

[69] A. A. Abdel-Azim, "Unsaturated polyester resins from poly(ethylene terephthalate) waste for polymer concrete," Polymer Engineering and Science, vol. 36, no. 24, pp. 2973-2977, 1996.

[70] K.S. Rebeiz, D. W. Fowler, and D. R. Paul, "Making polymer concrete with recycled PET," Plastics Engineering, vol. 47, no. 2, pp. 33-34, 1991.

[71] M. E. Tawfik and S. B. Eskander, "Polymer concrete from marble wastes and recycled poly(ethylene terephthalate)," Journal of Elastomers and Plastics, vol. 38, pp. 65-79, 2006.

[72] R. Siddique, J. Khatib, and I. Kaur, "Use of recycled plastic in concrete: A review," Waste Management, vol. 28, pp. 1835-1852, 2008.

[73] T. Ochi, S. Okubo, and K. Fukui, "Development of recycled PET fiber and its application as concrete-reinforcing fiber," Cement and Concrete Composites, vol. 29, pp. 448-455, 2007.

[74] C. Yun-Wang, M. Dae-Joong, C. Jee-Seung, and C. Sun-Kyu, "Effects of waste PET bottles aggregate on the properties of concrete," Cement and Concrete Research, vol. 35, pp. 776-781, 2005

[75] S. Gavela, C. Karakosta, C. Nydriotis, V Kaselouri-Rigopoulou, S. Kolias, P. A. Tarantili, C. Magoulas, D. Tassios, and A. Andreopoulos, "A study of concretes containing thermoplastic wastes as aggregates," presented at the Conference on the Use of Recycled Materials in Building and Structures, Barcelona, Spain, 2004.

[76] O. Y. Marzouk, R. M. Dheilly, and M. Queneudec, "Valorization of post-consumer waste plastic in cementitious concrete composites," Waste Management, vol. 27, pp. 310-318, 2007.

[77] P. Turgut and B. Yesilata, "Physico-mechanical and thermal performances of newly developed rubber-added bricks," Energy Build, vol. 40, pp. 679-88, 2008.

[78] B. Yesilata and P. Turgut, "Insulation property of rubberized mortar," $J$ Polytech., vol. 8, pp. 173-177, 2005.

[79] B. Yesilata, P. Turgut, and Y. Isiker, "Experimental investigation on insulation properties of polymeric-waste-added concretes," $J$ Therm Sci. Technol., vol. 26, pp. 15-20, 2006.

[80] B. Yesilata and P. Turgut, "A simple dynamic measurement technique for comparing thermal insulation performances of anisotropic building materials," Energy Build, vol. 39, pp. 1027-34, 2007.

[81] M. Nehdi and A. Khan, "Cementitious composites containing recycled tire rubber: An overview of engineering properties and potential applications," Cem Concr Aggr., vol. 23, pp. 3-10, 2001.

[82] R. Siddique and T. R. Naik, "Properties of concrete containing scrap-tire rubber - An overview," Waste Manage, vol. 24, pp. 563-569, 2004.

[83] S. Nienhuys, "Plastic waste insulation for high altitude areas," Unofficial Report, Senior Renewable Energy Advisor, SNV-Nepal, 26 June 2003 
[84] B. Yesilata, Y. Isıker, and P. Turgut, "Thermal insulation enhancement in concretes by adding waste PET and rubber pieces," Construction and Building Materials, vol. 23, pp. 1878-1882, 2009

[85] A. R. Khaloo and M. Afshari, "Cement and concrete composite," ELESVIER Journal, vol. 27, pp. 141-149, 2005.

[86] S. Faiz U. Ahmed, M. Maalej, and P. Parmasivam, "Construction and building materials, ELSEVIER Journals, vol. 21, pp. 1088-1097, 2007.

[87] L. Ombres, T. Alkhrdaji, and A. Nanni, "Flexural analysis of one way concrete slabs reinforced with GFRP rebars" International Meeting on Composite Materials, PLAST 2000, Milan, Italy, pp. 243-250.

[88] M. Andrea and B. Kanrod, "Fiber added concrete," presented at 2nd International PhD Symposium in Civil Engineering, Budapest.

[89] K. Ramadevi and R. Manju, "Experimental investigation on the properties of concrete with plastic PET (bottle) fibers as fine aggregates," International Journal of Emerging Technology and Advanced Engineering, vol. 2, issue 6, pp. 42-46, 2012.

[90] K. S. Rebeiz, S. P. Serhal, and D. W. Fowler, "Structural behavior of polymer concrete beams using recycled plastic," Journal of Materials in Civil Engineering, vol. 6, no. 1, pp. 150-165, 1994.

[91] R. N. Nibudey, P. B. Nagarnaik, D. K. Parbat, and A. M. Pande, "Strength and fracture properties of post consumed waste plastic fiber reinforced concrete," International Journal of Civil, Structural, Environmental and Infrastructure Engineering Research and Development (IJCSEIERD), vol. 3, issue 2, pp. 9-16, 2013.

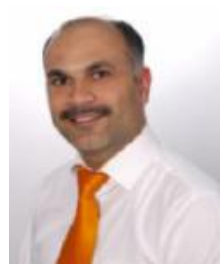

Mohamed Sulyman was born in 1976. He got his MSc. degree in 2008 from Academy of Graduate Studies and the B.Sc. degree in 2000 from Al-Mergheb University in the field of chemical engineering, Libya. Currently he is a PhD student at Polymer Technology Department, Gdańsk University of Technology in Poland. His area of research is chemical and environmental engineering.

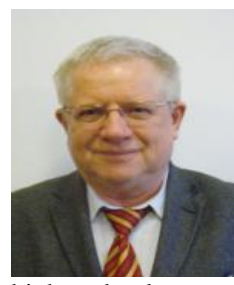

Jozef Haponiuk was born in 1950. He obtained his $\mathrm{PhD}$ title in 1979 from the Technische Hochschule Leuna Merseburg, Germany. Since 2006 he is the head of the Department of Polymer Technology at the Chemical Faculty of the Gdańsk University of Technology. His special scientific interests are chemistry, characterization and processing of polyurethanes, recycling of polymers and rubbers, biobased polymers, polymer composites and nanocomposites.

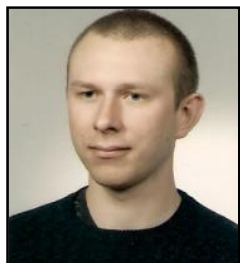

Krzysztof Formela was born in 1986. He obtained his $\mathrm{PhD}$ title in 2014 from Chemical Faculty, Gdansk University of Technology (Poland). He is employed at the Polymer Technology Department at the Chemical Faculty Gdansk University of Technology since 2014. Currently he is an assistant professor. His scientific interests are polymer chemistry and technology, polymer processing (especially extrusion and blending of polymers) and recycling of waste rubber. 